Exp. Anim. 63(4), 423-433, 2014

\title{
-Original-
}

\section{A Novel and Effective Balanced Intravenous-Inhalant Anaesthetic Protocol in Swine by Using Unrestricted Drugs}

\author{
Luigino CALZETTA ${ }^{1)}$, Piero ROSSI'), Pierluigi BOVE²), Pietro ALFONSI ${ }^{3)}$, Luigi BONIZZI ${ }^{4}$, \\ Paola RONCADA ${ }^{4,5)}$, Roberta BERNARDINI ${ }^{6}$, Edoardo RICCIARDI ${ }^{2)}$, Mauro MONTUORI ${ }^{2)}$, \\ Elena PISTOCCHINI ${ }^{6,7)}$, Paolo MAUTI ${ }^{8)}$, and Maurizio MATTEI ${ }^{6)}$
}

1)Laboratory of Systems Approaches and Non-Communicable Diseases, IRCCS San Raffaele Pisana, Via di Val Cannuta, 247-00166 Rome, Italy

${ }^{2)}$ Department of Surgery, University of Rome "Tor Vergata", Rome, Italy

3) ASL Roma B, UOC Igiene degli Allevamenti e delle Produzioni Zootecniche, Rome, Italy

4) Dipartimento di Scienze Veterinarie e Sanità Pubblica (DIVET), Università degli Studi di Milano, Milan, Italy

${ }^{5)}$ Istituto Sperimentale Italiano L. Spallanzani, Milan, Italy

6) Centro di Servizi Interdipartimentale, Stazione per la Tecnologia Animale, University of Rome "Tor Vergata", Rome, Italy

7) CDVet, Laboratorio Analisi Veterinarie, Rome, Italy

${ }^{8)}$ LED Spa, Aprilia (LT), Italy

\begin{abstract}
Nowadays, because of increasing employment of swine for experimental studies and medical training, it is hopeful to investigate novel and effective anaesthetic protocols for preserving the animal welfare in medical investigation and concurrently improving the quality of research. Therefore, the aim of this study was to investigate a novel and effective anaesthetic protocol in swine undergoing major surgery, by translating know-how of combined anaesthesia from human protocols. Seven landrace swine were anaesthetized for three hours by a combined trial anaesthetic protocol (sedation: medetomidine, acepromazine, atropine and tramadol; induction: propofol, medetomidine and acepromazine; anaesthesia: isofluorane, propofol, medetomidine and acepromazine) and both clinical and haemodynamic parameters were compared with those of five swine anaesthetized with a control protocol (sedation: diazepam, ketamine and atropina; induction: diazepam and ketamine; anaesthesia: isofluorane). Both cardiac frequency (CF) and mean blood pressure (MBP) were significantly $(P<0.05)$ more stable in trial protocol (CF: $78.3 \pm 4.6-81.1 \pm 5$, MBP: $63.9 \pm 10.7-96.4 \pm$ 13.0) compared to control protocol (CF: $93.7 \pm 5.5-102.5 \pm 8.5$, MBP: $71.0 \pm 6.6-108.7 \pm 7.2$ ). The body temperature remained stable in trial protocol $\left({ }^{\circ} \mathrm{C}: 36.9 \pm 0.7-37.2 \pm 0.3\right)$ compared to control anaesthesia $\left({ }^{\circ} \mathrm{C}: 36.4 \pm 0.3-37.3 \pm 0.2, P<0.05\right)$. Haematosis improved undergoing combined anaesthesia $(+2 \%, P<0.05)$ whereas did not change in control animals. There were no differences in respiratory rate between trial and control protocols. This study demonstrates that the proposed balanced intravenous-inhalant protocol permits to carry out a very effective, stable and safe anaesthesia in swine undergoing deep anaesthesia.
\end{abstract}

Keywords: balanced anaesthesia, hemodynamic evaluation, laboratory animals, swine 


\section{Introduction}

Swine are suitable experimental animals for many surgery techniques such as liver, kidney, heart, blood circulation and intestine. In effect, pigs have a significant morphological and functional similarities compared to human. Therefore, innovative surgical techniques have been firstly investigated in pigs for their feasibility, safety and efficacy. Furthermore, also pathophysiological investigations such as organ failure and sepsis have high validity in animal model based on swine [32]. In addition, the role of swine as a model employed in training for basic surgical techniques and for innovative procedures, such as new laparoscopy devices application, has also to be highlighted $[32,53]$. In fact, even though the research and training in pigs may present management and logistic complexity compared to small laboratory animals, the importance of these training procedures in swine has been broadly confirmed during the last decade $[2,13,26,32,33,46]$.

Even though the state-of-art of human anaesthesia has reached significant levels and it is continuously developing, the knowledge of swine anaesthesia in subjects undergoing surgery for medical research intents appears to be quite static $[3,60]$. Furthermore, as an increasing employment of swine for experimental studies and medical training, it seems to be necessary to investigate new and effective anaesthetic protocols for preserving animal welfare in medical investigation and concurrently improving the quality of research $[2,13$, 26, 33, 46].

In our opinion, the best way for investigating new anaesthetic protocols in swine is represented by a translational process of understanding from human anaesthetic protocols. Nevertheless, it has also to be addressed that a main actual issue to the research in veterinary anaesthesia is represented by law restrictions concerning many drugs that are commonly used in human but officially not allowed in animals, or for those drugs that requires specific permission for their use in animals such as opioids and dissociative compounds.

Therefore, the aim of this study was to investigate a novel and effective anaesthetic protocol in swine undergoing deep surgery, by translating and adapting the know-how of combined anaesthesia from human protocols, and exclusively employing drugs that are not under law restrictions in Europe. The rational of the proposed protocol was to elicit potential synergistic interaction among medications in order to reduce drug concentrations and, thus, to prevent adverse events.

\section{Materials and Methods}

The study was approved by the Institutional Animal Care and Use Committee (IACUC) of the University of Rome "Tor Vergata", Rome, Italy. All experiments were performed in accordance with European and Italian rules on animal experimentation (D.L.vo 116/92; 86/609/ CEE). The drugs and medications have been managed and administered by a veterinary doctor (DVM, PhD) specialized in surgery and anaesthesiology, with the support of a theatre assistant. The surgical procedures have been performed by a specialized medical doctor (MD) research team specialized in surgery. The scientific level and the adequacy for carrying out the trial have been approved by IACUC. Animal care, before and after experiments, were made only by trained personnel.

\section{Animals}

Twelve healthy landrace swines (11 female, 1 male), weighed $40.9 \pm 7.5 \mathrm{~kg}$ and $5.1 \pm 0.9$ months old, were obtained from an authorized and high quality breeding farm in the district of Rome and moved into the animal farm of the Department of Biology STA University of Rome "Tor Vergata" (Rome, Italy) ten days before the surgery sessions. Animals were randomly chosen from a homogeneous group in order to avoid significant individual variations concerning anatomy and physiology. Animals had not access to the water and feed 12 and 24 $\mathrm{h}$ before the surgery, respectively.

\section{Drugs}

The drugs used in the study were: acetylpromazine (ACE, $10 \mathrm{mg} / \mathrm{ml}$ ), atropine (ATR, $1 \mathrm{mg} / \mathrm{ml}$ ), diazepam (DIA, $5 \mathrm{mg} / \mathrm{ml}$ ), isofluorane (ISO), ketamine (KET, $100 \mathrm{mg} / \mathrm{ml}$ ), medetomidine (MED, $1 \mathrm{mg} / \mathrm{ml}$ ), lidocaine (LID, 2\%), propofol (PRO, $10 \mathrm{mg} / \mathrm{ml}$ ) and tramadol (TRA, $50 \mathrm{mg} / \mathrm{ml}$ ). In the paper the term "MIX" is referred to a mixture 50/50 (volume/volume) of MED/ ACE. All drugs were stored at room temperature and were bought by Demas S.r.L (Rome, Italy).

\section{Triage}

The body temperature $\left(38.4 \pm 0.4^{\circ} \mathrm{C}\right)$, the cardiac frequency $(\mathrm{CF})$ expressed as beats per minute (BPM, 88.6 \pm 18.9 ), the respiratory rate (RR) expressed as acts per 
Table 1. Piglet population and triage

\begin{tabular}{lc}
\hline Number (gender) & $12(11 \mathrm{~F} ; 1 \mathrm{M})$ \\
Age (months) & $5.1 \pm 0.9$ \\
Body weight $(\mathrm{kg})$ & $40.9 \pm 7.5$ \\
Body temperature $\left({ }^{\circ} \mathrm{C}\right)$ & $38.4 \pm 0.4$ \\
Cardiac frequency $(\mathrm{BPM})$ & $88.6 \pm 18.9$ \\
Gingival refill time (seconds) & $2.7 \pm 0.4$ \\
Respiratory rate $(\mathrm{APM})$ & $17.6 \pm 1.9$ \\
ASA & $1.6 \pm 0.4$ \\
\hline
\end{tabular}

Each value is the mean \pm CI of $n=12$ different subjects. BPM: beats per minute, APM: act per minute, ASA: physical status classification by American Society of Anaesthesiologists.

minute (APM, $17.6 \pm 1.9)$ and the gingival refill time $(2.7 \pm 0.4)$ were in the normal range at the pre-surgery clinical visit $[32,60]$. The physical status classification by American Society of Anaesthesiologists (ASA) was $1.6 \pm 0.4$ since some subjects were very sensitive to the handling-induced stress [23] (Table 1).

\section{Anaesthesia}

\section{1) Depth of anaesthesia}

The depth of anaesthesia has been continuously monitored during the trial and, in agreement with the surgical procedures performed on animals, pigs have been constantly maintained at a level of surgical anaesthesia, in agreement with the latest guidelines proposed for anaesthesia in laboratory animals and swine [24, 46]. In particular, the depth of anaesthesia has been regulated to perform "type III" procedures, in agreement with recommendations suggested by Boschert and colleagues for major surgery in pigs [8].

\section{2) Trial group}

Seven pigs were enrolled for studying the trial anaesthetic protocol as follows:

Preanaesthetic sedation

The preanaesthetic medication was intramuscular (IM) in the region of neck, injecting through one syringe ATR $0.02 \mathrm{mg} / \mathrm{kg}$, TRA $2.3 \mathrm{mg} / \mathrm{kg}$ and MIX $0.04 \mathrm{ml} / \mathrm{kg}$ $31.0 \pm 7.8 \mathrm{~min}$ before the induction of anaesthesia (Table 2).

Induction of anaesthesia

When animals were in sternal or lateral recumbency, a 22 standard wire gauge cannula was placed in the marginal auricular vein through which fluids $(\mathrm{NaCl} 0.9 \%$ at the rate of $8 \mathrm{ml} / \mathrm{kg} / \mathrm{h}$ ) and drugs were subsequently injected. The anaesthesia was inducted with intravenous (IV) MIX $0.02 \mathrm{ml} / \mathrm{kg}$ followed by PRO $3.2 \mathrm{mg} / \mathrm{kg}$. LID
$2 \%$ was sprayed on the larynx and the endotrachel intubation by $8.0-9.0 \mathrm{~mm}$ diameter tube was carried out (Table 2).

\section{Maintenance of anaesthesia}

After the induction of anaesthesia and tracheal intubation, automatic lung ventilation in a semi-closed circle was performed, setting the operation mode as assist controlled of intermittent positive pressure ventilation (IPPV-AC), the I/E ratio (1:2), the volume of gas inhaled and exhaled during one respiratory cycle (Tidal Volume, $14.5 \mathrm{ml} / \mathrm{kg}$ ), the positive end expiratory pressure (PEEP, $20 \mathrm{cmH}_{2} \mathrm{O}$ ) and the RR (>10 APM) by an AM Major 5000 anaesthesia machine combined with an Alpha Delta Lung Ventilator and a Siare Isofluorane Vaporizer. The fraction of inspired oxygen in the gas mixture (FiO2) was continuously monitored (Table 2).

The anaesthesia continued 180 minutes and maintained with ISO (from 1.3 to $2.4 \%$ ) vaporized in oxygen (from 1.8 to $2.2 \mathrm{l} / \mathrm{min}$ ) plus MIX (from 5.7 to $15.6 \mu \mathrm{l} /$ $\mathrm{kg} /$ hour, IV) and PRO (from 0.9 to $2.2 \mathrm{mg} / \mathrm{kg} / \mathrm{hour}$, IV) (Fig. 1, Table 3).

\section{3) Control group}

Five pigs were included into the control group and they were anaesthetised with a control anaesthetic protocol as previously reported by Tranquilli and colleagues, in agreement with the "Recommendations of the Consensus meeting on Ketamine Anaesthesia in Pigs" [8, 60]. Briefly, animals were sedated IM by injecting through one syringe DIA $1.5 \mathrm{mg} / \mathrm{kg}$ plus KET $14.0 \mathrm{mg} / \mathrm{kg}$ plus ATR $0.04 \mathrm{mg} / \mathrm{kg}$. After that, animals were inducted IV with DIA $1.0-2.0 \mathrm{mg} / \mathrm{kg}$ plus KET $10.0-18.0 \mathrm{mg} / \mathrm{kg}$ to effect and the anaesthesia was maintained with ISO $4 \%$ in oxygen $21 / \mathrm{min}$ (Tables 2 and 3).

\section{Surgical procedure}

The anaesthesia was performed in animals undergoing bloodless kidney resection and partial nephrectomy by an incremental, bipolar radiofrequency generator with multi electrode probe, as previously described $[53,54]$. In particular, animals were supine for laparotomy surgery by performing intestinal loops mobilization for partial nephrectomy after artery and vein isolation. At the end of surgical procedure, animals were managed in accordance with the European guidelines (86/609/CEE) and Italian laws (D.L.vo 116/92) concerning the animal testing regulation and welfare [29]. 
Table 2. Main clinical records, procedures, anaesthetics devices setting and drugs administration

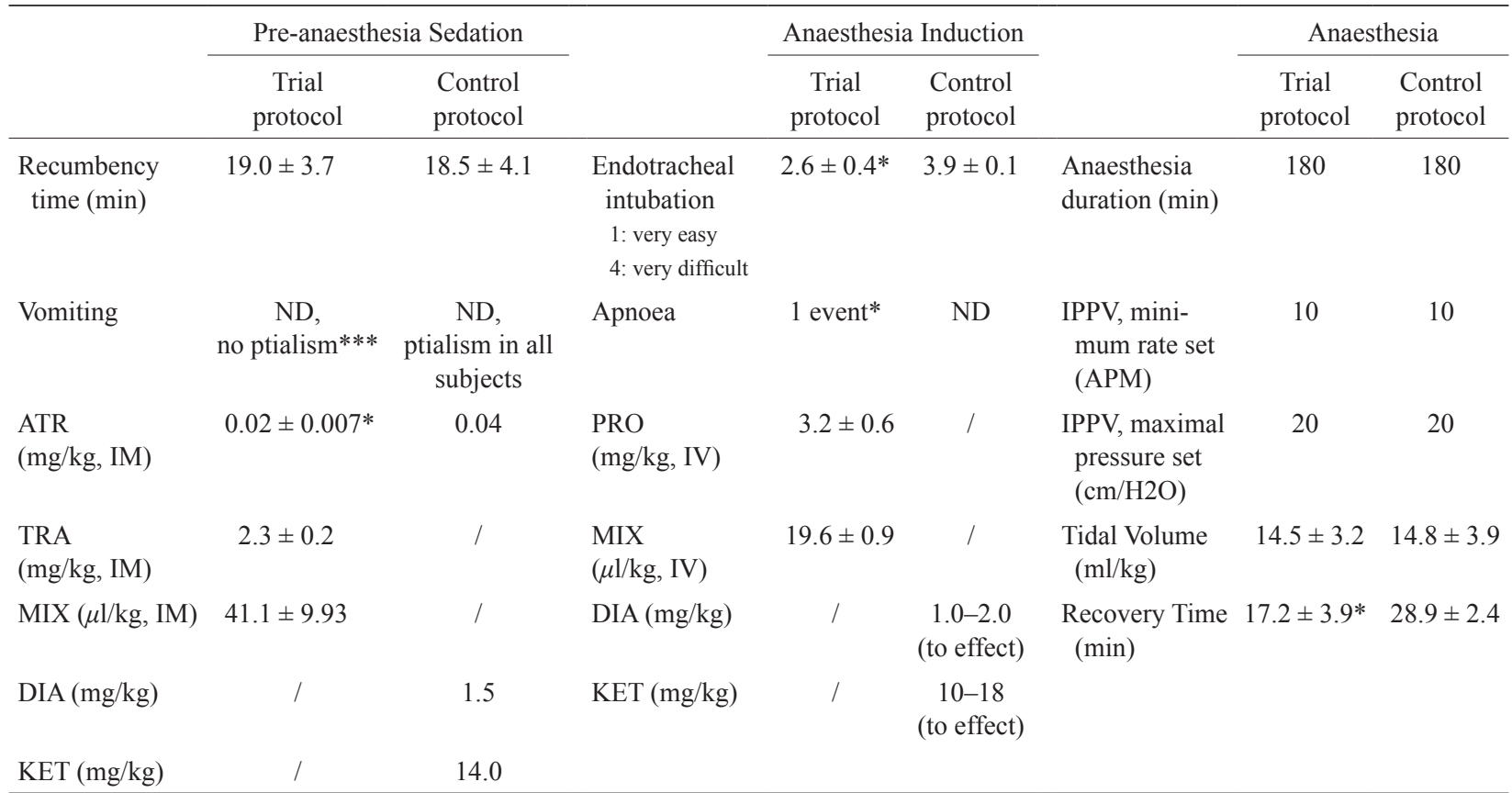

Each value is the mean $\pm \mathrm{CI}$ of control $(\mathrm{n}=5)$ and trial $(\mathrm{n}=7)$ protocols. ATR: atropine, DIA: diazepam, IPPV: intermittent positive pressure ventilation, KET: ketamine TRA: tramadol, MIX: a mixture 50/50 (volume/volume) of MED (0.1\%) / ACE (1\%), ND: not detected, PRO: propofol, IPPV: intermittent positive pressure ventilation; Tidal Volume: the volume of gas inhaled and exhaled during one respiratory cycle, ND: not detected TRA: tramadol; ${ }^{*} P<0.05,{ }^{* * *} P<0.001$ vs. control group.

\section{1) Hemodynamic monitoring}

The electrocardiogram, the respiration, the non-invasive blood pressure, the temperature and the oxygen saturation $\left(\mathrm{SpO}_{2}\right)$ were continuously monitored by a Mindray patient monitor MEC-1200.

\section{2) Statistic analysis}

Statistical analysis was performed by using the software GraphPad Prism version 5.00 for Windows. All values are presented as mean $\pm \mathrm{CI}$ and the statistical significance was assessed by Student's $t$ test or one-way analysis of variance (ANOVA), with Dunnett's or Bonferroni post-tests when necessary. Appropriate curvefitting to polinomial models were used to graph the results. The level of statistical significance was defined as $P<0.05$ compared to control group [48].

\section{Results}

The preanaesthetic sedation permitted an adequate placement of the IV catheter in the ear veins of all piglets. Nor vomiting nor nausea was detected and animals lay down softly in $19.0 \pm 3.7$ min without differences to control group $(P>0.05)$ (Table 2$)$. In trial protocol ani- mals did not manifested ptialism compared to subjects of control group where this symptom was often detected $(P<0.001)$.

All piglets of trial protocol had a soft and rapid induction of anaesthesia. One event of apnoea was detected through PRO induction and it was successfully managed by mechanical ventilation. On the contrary, the sedation of control group was characterized by muscular rigidity and tremors.

The intubation difficulty was $2.6 \pm 0.74$ for trial group, in a range-scale from 1 to 4 (1: very easy, 2: normal, 3: difficult and 4: very difficult intubation) and it was significantly easier compared to control group $(3.9 \pm 0.1$, $P<0.05)$. Furthermore, the swallowing reflex was manifested in one subject of the trial group during the intubation procedure, and deepening the level of anaesthesia with PRO effectively abolished it.

The CF did not significantly change, ranging from $78.3 \pm 4.6$ to $81.1 \pm 5.5 \mathrm{BPM}$ during the anaesthesia maintenance in the trial group and was significantly $(P<0.05)$ more stable compared to control group.

The mean blood pressure significantly $(P<0.001)$ decreased from $96.45 \pm 13.00 \mathrm{mmHg}$ ( $1^{\text {st }}$ hour $)$ to $63.90 \pm$ $10.72 \mathrm{mmHg}$ ( $3^{\text {rd }}$ hour) in absence of bleeding. The 


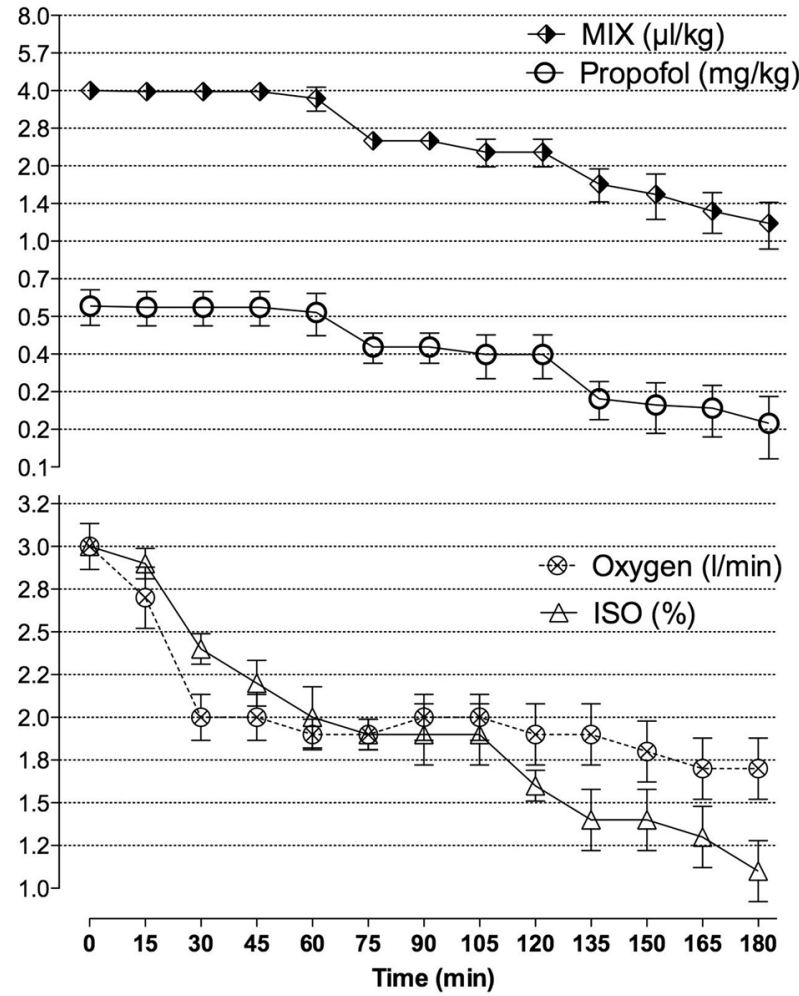

Fig. 1. Timetable for administrating MIX, PRO, ISO and oxygen along three hours of anaesthesia with the balanced protocol. Each value is the mean \pm CI of $n=7$ different subjects. MIX: a mixture 50/50 (volume/volume) of MED (0.1\%)/ACE (1\%), PRO: propofol, ISO: isofluorane.

systolic and diastolic blood pressures also shown a significant $(P<0.001)$ reduction during anaesthesia. Even though the blood pressure decreased in the trial group, values were always maintained into the normal range for an adequate cerebral, renal and coronary perfusion and did not show any significant $(P<0.01)$ peak as that detected at $2^{\text {nd }}$ hour in control group (maximal pressure $145.0 \pm 5.0 \mathrm{mmHg}$ ) [60] (Table 4).

The $\mathrm{SpO}_{2}$ value significantly $(P<0.05)$ increased during anaesthesia of trial group, whereas it did not improved during anaesthesia in control group and $\mathrm{FiO}_{2}$ remained unchanged in both groups (Table 4).

The body temperature was $37.2 \pm 0.3{ }^{\circ} \mathrm{C}$ at the beginning of anaesthesia and remained stable in the trial group, whereas the temperature slightly dropped out at $3^{\text {rd }}$ hour in control animals $(P<0.05)$ (Table 4).

The RR ranged from $14.95 \pm 1.80 \mathrm{APM}\left(1^{\text {st }}\right.$ hour $)$ to $12.15 \pm 2.25 \mathrm{APM}\left(3^{\text {rd }}\right.$ hour$)$ in trial group and was not significantly different to control anaesthesia $(P>0.05)$ (Table 4).
The muscle relaxation and the intra-operatory analgesia induced by the trial protocol were good as detected by surgeons and by vital sings [60]. On the contrary, an IV administration of DIA (bolus to effect) was required in the control group at both 60 and 120 min of anaesthesia since the muscle relaxation induced by control anaesthesia was not adequate [15, 37].

The recovery time, calculated as the period of time between the end of all anaesthetic drugs administration and the restore of the mandibular muscle tone, was 17.20 $\pm 3.90 \mathrm{~min}$ for the trial protocol, significantly shorter than that relived for the control protocol $(P<0.05)$ (Table 2).

\section{Discussion}

The present study demonstrated that the proposed novel balanced intravenous-inhalant protocol for anaesthesia was effective, haemodynamically stable and safe in swine undergoing a medium-long term major surgery session. These goals have been gained by exclusively employing drugs that are not under law restriction in Europe.

Even though some drugs used in this protocol usually produce depressant effects of the cardio-respiratory system when administered under different conditions or alone $[7,15,30,38,39,49,51,58]$, paradoxically our combined anaesthetic protocol was very effective in maintaining the hemodynamic homeostasis along all the time of surgery. In effect, the cardiac frequency was constant, neither hypotension nor hypertension was recorded and the body temperature did not alter. The unique adverse event was an episode of apnoea during anaesthesia induction that was easily managed [35].

Specifically, the surgical procedure, requiring very small laparotomy, provided the isolation of renal pedicle and clamping artery and veins about $75 \mathrm{~min}$ after beginning of anaesthesia for partial nephrectomy. We highlight that, undergoing our anaesthetic protocol, this surgical procedure did not induce any evident haemodynamic modification compared to previous findings that documented an increasing of CF followed by a harmless compensatory decline of the blood pressure $[2,55]$. In addition, the body temperature did not decreased, although this finding might be correlated with the short laparotomy.

Another attractive result concerns the improvement of haematosis induced by our protocol. The $\mathrm{SpO}_{2}$ enhanced of about $2 \%$ along the anaesthesia session and 
Table 3. Gas and drugs administration for anaesthesia maintenance

\begin{tabular}{lccccc}
\hline & \multicolumn{3}{c}{ Trial protocol } & & Control protocol \\
\cline { 2 - 3 } & $1^{\text {st }}$ hour & $2^{\text {nd }}$ hour & $3^{\text {rd }}$ hour & & $1^{\text {st }}$ to $3^{\text {rd }}$ hour \\
\hline Oxygen $(1 / \mathrm{min})$ & $2.2 \pm 0.3$ & $2.0 \pm 0.1$ & $1.8 \pm 0.1$ & & 2.0 \\
ISO $(\%)$ & $2.4 \pm 0.3 *$ & $1.8 \pm 0.1 *$ & $1.3 \pm 0.1 *$ & 4 \\
MIX $(\mu \mathrm{l} / \mathrm{kg} /$ hour, IV) & $15.62 \pm 0.11$ & $9.60 \pm 0.13$ & $5.74 \pm 0.19$ & \\
PRO $(\mathrm{mg} / \mathrm{kg} /$ hour, IV) & $2.15 \pm 0.01$ & $1.46 \pm 0.01$ & $0.86 \pm 0.02$ & & $/$ \\
\hline
\end{tabular}

Each value is the mean $\pm \mathrm{CI}$ of control $(\mathrm{n}=5)$ and trial $(\mathrm{n}=7)$ protocols. ISO: isofluorane, MIX: a mixture $50 / 50$ (volume/volume) of MED (0.1\%) / ACE (1\%), PRO: propofol; ${ }^{*} P<0.05$ vs. control group.

Table 4. Vital parameters recorded along three hour of deep anaesthesia

\begin{tabular}{|c|c|c|c|c|c|c|}
\hline & \multicolumn{3}{|c|}{ Trial protocol } & \multicolumn{3}{|c|}{ Control protocol } \\
\hline & $1^{\text {st }}$ hour & $2^{\text {nd }}$ hour & $3^{\text {rd }}$ hour & $1^{\text {st }}$ hour & $2^{\text {nd }}$ hour & $3^{\text {rd }}$ hour \\
\hline Cardiac Frequency (BPM) & $78.3 \pm 4.6$ & $80.7 \pm 5.0^{\S}$ & $81.1 \pm 5.5^{\S}$ & $93.7 \pm 5.5$ & $102.5 \pm 8.5^{*}$ & $96.2 \pm 1.25^{* *}$ \\
\hline Systolic Blood Pressure (mmHg) & $116.9 \pm 9.6$ & $98.6 \pm 8.3^{* * *} \S \S$ & $91.2 \pm 8.9^{* * *}$ & $111.2 \pm 3.1$ & $133.7 \pm 5.5^{* *}$ & $107.5 \pm 4.8^{* *}$ \\
\hline Mean Blood Pressure $(\mathrm{mmHg})$ & $96.4 \pm 13.0$ & $75.1 \pm 9.5^{* * *} \S$ & $63.9 \pm 10.7^{* * *}$ & $78.7 \pm 5.1$ & $108.7 \pm 7.2^{* *}$ & $71.0 \pm 6.6$ \\
\hline Diastolic Blood Pressure (mmHg) & $80.4 \pm 12.7$ & $61.1 \pm 10.4^{* * *}$ & $52.9 \pm 12.4^{* * *}$ & $61.2 \pm 3.1$ & $86.3 \pm 2.4^{* * *}$ & $56.3 \pm 3.7$ \\
\hline Respiratory Rate (ATM) & $14.9 \pm 1.8$ & $13.0 \pm 2.3$ & $12.1 \pm 2.2$ & $14.0 \pm 2.0$ & $13.5 \pm 2.5$ & $12.5 \pm 2.1$ \\
\hline $\mathrm{SpO}_{2}(\mathrm{mmHg})$ & $96.1 \pm 1.2$ & $98.0 \pm 0.8^{* *} \S$ & $97.6 \pm 0.6^{* \S}$ & $95.3 \pm 0.9$ & $95.5 \pm 0.7$ & $94.9 \pm 1.8^{*}$ \\
\hline $\mathrm{FiO}_{2}(\%)$ & $88.8 \pm 3.7$ & $90.3 \pm 3.1$ & $91.1 \pm 2.9$ & $90.2 \pm 3.1$ & $89.7 \pm 3.0$ & $89.5 \pm 3.7$ \\
\hline Body Temperature $\left({ }^{\circ} \mathrm{C}\right)$ & $37.2 \pm 0.3$ & $37.1 \pm 0.5$ & $36.9 \pm 0.7$ & $37.3 \pm 0.2$ & $36.9 \pm 0.5$ & $36.4 \pm 0.3^{*}$ \\
\hline
\end{tabular}

Each value is the mean $\pm \mathrm{CI}$ of control $(\mathrm{n}=5)$ and trial $(\mathrm{n}=7)$ protocolsEach value is the mean $\pm \mathrm{CI}$ of $\mathrm{n}=7$ different subjects. BPM: beats per minute, ATM: acts per minute, $\mathrm{SpO}_{2}$ : oxygen saturation, $\mathrm{FiO}_{2}$ : fraction of inspired oxygen in the gas mixture; ${ }^{*} P<0.05$ vs. $1^{\text {st }}$ hour, ${ }^{* *} P<0.01$ vs. $1^{\text {st }}$ hour, ${ }^{* * *} P<0.001$ vs. $1^{\text {st }}$ hour; ${ }^{\circledR} P<0.05$ and ${ }^{\S} P<0.01$ vs. control group.

this effect might be referred to the potent peripheral alpha receptor antagonism induced by the tranquilizer ACE. In effect ACE, a central dopaminergic receptor blocker at level of basal ganglia, forebrain, chemoreceptor trigger zone and hypothalamus, could improve the arterial oxygenation by inducing vasorelaxation in the pulmonary vascular bed and by reducing the pulmonary arteriovenous shunt in swine as previously suggested for different species $[5,9,45]$. In fact, it was demonstrated that during anaesthesia, the impaired arterial oxygenation can be attributed to an increased shunt and ventilation-perfusion ratio mismatch [45]. Therefore, the administration of ACE as a pre-anaesthetic drug could permit to prevent some of the anaesthesia-induced ventilation-perfusion ratio mismatch.

The improvement of haematosis might also be related to the peculiar approach provided by our protocol, which consist of a mixture of inhalant and IV drugs. In effect, it has been reported that volatile anaesthetics decrease the arterial $\mathrm{SpO}_{2}$ by inhibiting hypoxic pulmonary vasoconstriction. This autonomic regulatory mechanism of pulmonary circulation diverts blood flow away from poorly aerated lung areas, thereby improving ventilationperfusion ratio $[6,20,36]$. Therefore, the inhibition of this local vasoconstriction by volatile anaesthetics modifies the distribution of blood flow in the lung, mismatching the ventilation-perfusion ratio [36]. In our anaesthetic protocol, the gas exchange disturbances was probably less considerable because of the low dose of inhalants, balanced by the IV anaesthetics for maintaining an adequate level of anaesthesia required for major surgery.

In human, the popularity of TIVA by PRO is now a very attractive alternative compared to volatile anaesthetics. It has some advantages such as hemodynamic stability, stable depth of anaesthesia, predictable and rapid recovery, lower total dose of drug, reduced postoperative nausea and vomiting, less pollution and toxicity than that produced by volatile agents [19, 22, 42]. Furthermore, it was confirmed that PRO decreases plasma catecholamine concentrations reducing the adrenergic response to surgical stress [40, 41]. In addition, it has been also demonstrated that PRO may be effective in preventing bronchospasm in human during sedation [52]. Unfortunately, even though PRO has a good safety profile, it may also induce side effects that, in very sporadic cases, might be really dangerous for the health of patients. Particularly, the respiratory depression and apnea, the dose-dependent hypotension, the hypertriglyceridemia-associated pancreatitis and the generation 
of oxygen free radicals have been reported. In addition, high doses of PRO infusion have been associated with severe metabolic acidosis and circulatory collapse [14, $27,28,44]$. Therefore, the concomitant use of ISO in our combined anaesthetic protocol permitted to reduce the concentrations of PRO, preserving its haemodinamyc advantages and avoiding potential side effects.

The rational for using the potent and highly selective $\alpha 2$ adrenoreceptor agonist MED in this balanced anaesthetic protocol was related to its sedative, analgesic and muscle relaxant characteristics. The administration of ATR, a non-selective anticholinergic drug, and of ACE, characterized by antiemetic and antiarrhythmic effects, permitted to completely avoid the potential cardiopulmonary dysfunction related to the administration of $\operatorname{MED}[9,12,57]$. In fact, in no animal arrhythmias, hyper/hypotension, vomiting and nausea were detected. Moreover, together with PRO, MED induced an excellent muscle relaxation [15, 57].

This novel anaesthetic protocol also included the administration of TRA, an analgesic drug with mixed opioid and nonopioid activities used both in humans and animals as a pre-medication compound [1]. The IM administration of TRA permitted to reduce the stress, to facilitate intubation, to reduce the dose of induction agents and to improve the recovery time, as previously reported in different anaesthetic protocols in piglet $[1,41]$. Moreover, it has been reported that TRA produces synergistic interaction with MED on analgesia and with ACE on sedation [1, 9, 57]. Furthermore, a practice advantage of TRA is that in many countries the regulation concerning its use is less strict than for other opioids [43].

Although some authors reported the presence of reflexes at a superficial/mild level of anaesthesia in swine, even proposing a checklist of reflexes [32,33], we did not monitor the level of anaesthesia by evaluating reflexes. In fact, it has been proved that somatic reflexes could be ineffective to adequately establish the depth of surgical anaesthesia in swine [60]. Also the cornealpalpebral reflexes is not a good indicator for evaluating the depth of anaesthesia, being it often absent during anaesthesia and even weak in deep sedation $[13,25,26,58]$. Therefore, we did not evaluate somatic reflexes during the surgery sessions. On the other hand, our findings are consistent with those of other Authors that consider the increase of heart/respiratory rate and blood pressure the most sensitive indicators of a light plane of anaesthesia and pain in swine [13, 24-26, 46, 58]. Effectively, this monitoring approach permitted to constantly maintain the depth of anaesthesia at the level of surgical anaesthsia, in agreement with the most recent guidelines proposed by Flecknell and Swindle for anaesthesia in laboratory animals and swine [24, 46]. Therefore, our protocol has been validated in animal undergoing surgery sessions, also providing effective analgesia during all the surgery procedures.

The main issue of this experimental protocol was related to a long-lasting time for recumbency after IM sedative mixture administration ( $17 \mathrm{~min})$, which probably might interfere with the workflow of clinical practice in a laboratory animal farm. However, the knowledge of the recumbency time allows optimizing the procedure timing for managing the patient before the induction of anaesthesia.

All hemodynamic variations recorded throughout the three hours of anaesthesia were completely into a normal range of physiological parameters for swine. Furthermore, we did not record adverse events related to hyperthermia $[32,60]$. On the contrary, the proposed balanced anaesthetic protocol improved the haematosis in all swine undergoing major surgery.

In the last decade, the development of new protocols for balanced anaesthesia has been carried out in human $[17,18,21,34,47,50]$, whereas the last two papers about balanced anaesthesia in swine were from $90^{\text {th }}$ years $[16,56]$. Effectively, in veterinary practice inhalant anesthetic agents are the preferred method for maintenance of general anaesthesia since they are easy to be administered, the depth of anaesthesia can be rapidly and predictably modulated, and the recovery time is rapid [31].

Specifically in large laboratory animals such as swine, inhalant drugs are usually administered alone to maintain anaesthesia, and balanced anaesthetic techniques are rarely used. Unfortunately, cardiopulmonary function is reduced in dose-dependent fashion by inhalant drugs, and deepening the level of anaesthesia to modify autonomic responses to noxious stimuli may increase morbidity and mortality [11, 31]. In fact, although the inhalants induce a state of unconsciousness, deep levels of anaesthesia may not block many of the reflex responses to noxious stimuli which occur during surgery. The attempts to inhibit these responses by increasing the inhalant concentrations might induce severe cardiovascular and respiratory depression that, in turn, induce inadequate perfusion of vital organs even in young healthy 
Table 5. Practical guidelines for combined anaesthesia in a $40 \mathrm{~kg}$ swine

\begin{tabular}{lccccc}
\hline & \multirow{2}{*}{$\begin{array}{c}\text { Pre-anaesthesia } \\
\text { sedation }\end{array}$} & $\begin{array}{c}\text { Anaesthesia } \\
\text { induction }\end{array}$ & \multicolumn{3}{c}{ Anaesthesia maintenance } \\
\cline { 5 - 7 } & & & $1^{\text {st }}$ hour & $2^{\text {nd }}$ hour & $3^{\text {rd }}$ hour \\
\hline ATR $(\mathrm{ml})$ & 0.7 & & & & \\
TRA $(\mathrm{ml})$ & 1.9 & 0.8 & 0.6 & 0.4 & 0.2 \\
MIX $(\mathrm{ml})$ & 1.6 & 12.7 & 8.6 & 5.8 & 3.4 \\
PRO $(\mathrm{ml})$ & & & 2.4 & 1.8 & 1.3 \\
ISO $(\%)$ & & &
\end{tabular}

patients. In ASA 3 and 4 subjects, also light levels of inhalant anaesthetics may be too depressant and hemodynamic responses, such as tachycardia and hypertension, may occur even when anaesthetic concentrations of inhalant agents are high enough to prevent sensory, motor, and respiratory responses $[4,31]$. Furthermore, there are findings suggesting that while halothane was able to block the cardiovascular response to incision in dose-dependent manner, increasing the concentrations of ISO did not necessarily suppress this response [61]. Moreover, inhalant agents administered alone are unable to suppress any of the immunologic responses to stress, resulting in alteration of cellular immunity in patients undergoing deep surgery, with increased risk of sepsis and mortality [31, 59].

On the other hand, balanced intravenous inhalant anaesthesia can partially or completely suppress both hemodynamic and immunologic responses to surgical stimuli and balanced anaesthetic techniques are beneficial in offering a multidimensional approach to pain management. In fact not only do they block autonomic responses to surgical stimuli intraoperatively and provide analgesia during the postoperative period, but they may preempt the postoperative pain hypersensitivity state which potentially allows better pain management with lower doses of analgesics. Therefore, balanced anaesthesia performed at low concentrations of inhalant anaesthetics, combined with other drugs which modify reflex responses to noxious stimulation, may be effective in reducing patient morbidity and mortality and provide the veterinarian with smoother operating conditions [31].

These evidences offer the scientific rationale for using the proposed balanced intravenous-inhalant anaesthetic protocol in swine undergoing deep anaesthesia. Unfortunately, the lacking of scientific data on balanced anaesthesia carried out in laboratory animals and in swine makes very tough comparing our balanced intravenousinhalant protocol with other anaesthetic methods that do not involve a balanced approach, also because one of our aims was to validate a novel protocol by employing exclusively unrestricted drugs. In any case, we can indirectly speculate that the outcomes of our protocol were at the least equal/non-inferior compared with those of balanced protocols proposed by Sims and colleagues and by Dyess and colleagues in swine $[16,56]$. Certainly, the effectiveness and safety of our novel protocol was significantly superior compared with the balanced anaesthetic protocol used as control in this study, based on the administration of KET plus DIA and followed by inhalant ISO, at the least for performing type III surgical procedures [8].

The lacking of novel evidence-based protocols for balanced anaesthesia in pigs suggests a strong medical need in laboratory animals investigations, also considering the relevance of swine as a model for surgery techniques that will be translated in medical applications for humans.

The rational of the proposed anaesthetic protocol was to obtain the best drug effectiveness associated with the fewest side effects, via combining low doses of medications in order to produce synergistic interaction between agents and, thus, reducing adverse events [10]. The small amount of drugs administered adds the further advantage of reducing the potential interference of anaesthetic drugs with experimental results. Although this approach might increases the complexity of the anaesthetic protocol, certainly the outcomes (safety and the effectiveness) of the proposed protocol are of higher level compared with those of a conventional anaesthesia induced with the combination of dissociative medications plus benzodiazepines and maintained with inhalant agents. Therefore, in order to simplify the comprehension and the feasibility of our protocol, in Table 5 we suggest the practical guidelines for applying our anaesthetic protocol in swine of about $40 \mathrm{~kg}$.

Concluding, our findings demonstrate that the proposed balanced intravenous-inhalant protocol permits to obtain a stable and safe anaesthesia, that is effective for 
experimental procedures in swine undergoing major surgery.

\section{Acknowledgment}

We acknowledge 2LED Spa, Via Selciatella, 40 04011 Aprilia (LT), Italy, for their support in this study and providing for medical equipments and supplies.

\section{References}

1. Ajadi, A.R., Olusa, T.A., Smith, O.F., Ajibola, E.S., Adeleye, O.E., Adenubi, O.T., and Makinde, F.A. 2009. Tramadol improved the efficacy of ketamine-xylazine anaesthesia in young pigs. Vet. Anaesth. Analg. 36: 562-566. [Medline] [CrossRef]

2. Alric, P., Ryckwaert, F., Branchereau, P., Marty-Ané, C., Mary, H., and Colson, P. 2003. A porcine model of systemic and renal haemodynamic responses to infrarenal aortic cross-clamping. Eur. J. Vasc. Endovasc. Surg. 25: 72-78. [Medline] [CrossRef]

3. Barash, P.G.C.B., Stoelting, R.K., and Cahalan, M. Clinical Anesthesia. Sixth ed: Lippincott Williams \& Wilkins 2009.

4. Bednarski, R.M. 1989. Anesthesia and pain control. Vet. Clin. North Am. Small Anim. Pract. 19: 1223-1238. [Medline]

5. Berk, J.L., Hagen, J.F., and Koo, R. 1976. Effect of alpha and beta adrenergic blockade on epinephrine induced pulmonary insufficiency. Ann. Surg. 183: 369-376. [Medline] [CrossRef]

6. Bjertnaes, L.J., Hauge, A., and Torgrimsen, T. 1980. The pulmonary vasoconstrictor response to hypoxia. The hypoxiasensitive site studied with a volatile inhibitor. Acta Physiol. Scand. 109: 447-462. [Medline] [CrossRef]

7. Bollen, P.J., Nielsen, B.J., and Toft, P. 2007. Influence of endotoxin-induced sepsis on the requirements of propofolfentanyl infusion rate in pigs. Basic Clin. Pharmacol. Toxicol. 101: 192-196. [Medline] [CrossRef]

8. Boschert, K., Flecknell, P.A., Fosse, R.T., Framstad, T., Ganter, M., Sjøstrand, U., Stevens, J., Thurman, J., Ketamine Consensus Working Group 1996. Ketamine and its use in the pig. Recommendations of the Consensus meeting on Ketamine Anaesthesia in Pigs, Bergen 1994. Lab. Anim. 30: 209-219. [Medline] [CrossRef]

9. Brock, N. 1994. Acepromazine revisited. Can. Vet. J. 35 : 458-459. [Medline]

10. Calzetta, L., Page, C.P., Spina, D., Cazzola, M., Rogliani, P., Facciolo, F., and Matera, M.G. 2013. Effect of the mixed phosphodiesterase 3/4 inhibitor RPL554 on human isolated bronchial smooth muscle tone. J. Pharmacol. Exp. Ther. 346: 414-423. [Medline] [CrossRef]

11. Clarke, K.W. and Hall, L.W. 1990. A survey of anaesthesia in small animal practice: AVA/BSAVA report. J. Vet. Auaesth. 17: 4-10. [CrossRef]

12. Cullen, L.K. 1996. Medetomidine sedation in dogs and cats: a review of its pharmacology, antagonism and dose. Br. Vet. J. 152: 519-535. [Medline] [CrossRef]
13. Damy, S.B., Camargo, R.S., Chammas, R., Figueiredo, L., and Francisco, P. 2010. The fundamentals of experiments with animals - applications in experimental surgery. Rev. Assoc. Med. Bras. 56: 103-111. [Medline] [CrossRef]

14. Devlin, J.W., Lau, A.K., and Tanios, M.A. 2005. Propofolassociated hypertriglyceridemia and pancreatitis in the intensive care unit: an analysis of frequency and risk factors. Pharmacotherapy 25: 1348-1352. [Medline] [CrossRef]

15. Duke, T. 1995. A new intravenous anesthetic agent: propofol. Can. Vet. J. 36: 181-183. [Medline]

16. Dyess, D.L., Tacchi, E., Powell, R.Q., Ardell, J.L., Roberts, W.S., and Ferrara, J.J. 1994. Development of a protocol to provide prolonged general anesthesia to pregnant sows. $J$. Invest. Surg. 7: 235-242. [Medline] [CrossRef]

17. Eberhart, L.H., Eberspaecher, M., Wulf, H., and Geldner, G. 2004. Fast-track eligibility, costs and quality of recovery after intravenous anaesthesia with propofol-remifentanil versus balanced anaesthesia with isoflurane-alfentanil. Eur. J. Anaesthesiol. 21: 107-114. [Medline]

18. Eberhart, L.H., Folz, B.J., Wulf, H., and Geldner, G. 2003. Intravenous anesthesia provides optimal surgical conditions during microscopic and endoscopic sinus surgery. Laryngoscope 113: 1369-1373. [Medline] [CrossRef]

19. Eikaas, H. and Raeder, J. 2009. Total intravenous anaesthesia techniques for ambulatory surgery. Curr. Opin. Anaesthesiol. 22: 725-729. [Medline] [CrossRef]

20. Eisenkraft, J.B. 1990. Effects of anaesthetics on the pulmonary circulation. Br. J. Anaesth. 65: 63-78. [Medline] [CrossRef]

21. Epple, J., Kubitz, J., Schmidt, H., Motsch, J., Böttiger, B.W., Martin, E., and Bach, A. 2001. Comparative analysis of costs of total intravenous anaesthesia with propofol and remifentanil vs. balanced anaesthesia with isoflurane and fentanyl. Eur. J. Anaesthesiol. 18: 20-28. [Medline] [CrossRef]

22. Eyres, R. 2004. Update on TIVA. Paediatr. Anaesth. 14: 374-379. [Medline] [CrossRef]

23. Fehrenbach, M.J. ASA Physical Status Classification System. 2007.

24. Flecknell, P. Laboratory animal anaesthesia. 3rd ed: Academic Press; 2009.

25. Gaviria, E.J., Restrepo, J.G., MarÌn, J.D., Arango, G., Aramburo, D., Franco, F., and Tintinago, L.F.U.a. 2007. Evaluation of propofol as an anesthetic in swine tracheal transplant surgery. Rev. Colomb. Cienc. Pecuarias 20: 447-454.

26. Geovanini, G.R., Pinna, F.R., Prado, F.A., Tamaki, W.T., and Marques, E. 2008. Standardization of anesthesia in swine for experimental cardiovascular surgeries. Rev. Bras. Anestesiol. 58: 363-370. [Medline]

27. Glowaski, M.M. and Wetmore, L.A. 1999. Propofol: application in veterinary sedation and anesthesia. Clin. Tech. Small Anim. Pract. 14: 1-9. [Medline] [CrossRef]

28. Gottschling, S., Larsen, R., Meyer, S., Graf, N., and Reinhard, H. 2005. Acute pancreatitis induced by short-term propofol administration. Paediatr. Anaesth. 15: 1006-1008. [Medline] [CrossRef]

29. Gregory, S.P., Waterman, A.E., and Weaver, B.M. 1991. Method of euthanasia in animal study. Radiology 179: 288. [Medline] [CrossRef] 
30. Hayashi, K., Nishimura, R., Yamaki, A., Kim, H., Matsunaga, S., Sasaki, N., and Takeuchi, A. 1994. Comparison of sedative effects induced by medetomidine, medetomidinemidazolam and medetomidine-butorphanol in dogs. J. Vet. Med. Sci. 56: 951-956. [Medline] [CrossRef]

31. Ilkiw, J.E. 1999. Balanced anesthetic techniques in dogs and cats. Clin. Tech. Small Anim. Pract. 14: 27-37. [Medline] [CrossRef]

32. Kaiser, G.M., Heuer, M.M., Frühauf, N.R., Kühne, C.A., and Broelsch, C.E. 2006. General handling and anesthesia for experimental surgery in pigs. J. Surg. Res. 130: 73-79. [Medline] [CrossRef]

33. Kaiser, G.M., Breuckmann, F., Aker, S., Eggebrecht, H., Kuehl, H., Erbel, R., Fruhauf, N.R., Broelsch, C.E., and Quick, H.H. 2007. Anesthesia for cardiovascular interventions and magnetic resonance imaging in pigs. J. Am. Assoc. Lab. Anim. Sci. 46: 30-33. [Medline]

34. Ke, J.J., Zhan, J., Feng, X.B., Wu, Y., Rao, Y., and Wang, Y.L. 2008. A comparison of the effect of total intravenous anaesthesia with propofol and remifentanil and inhalational anaesthesia with isoflurane on the release of pro- and antiinflammatory cytokines in patients undergoing open cholecystectomy. Anaesth. Intensive Care 36: 74-78. [Medline]

35. Kimme, P., Ledin, T., and Sjöberg, F. 2007. Dose effect of sevoflurane and isoflurane anesthetics on cortical blood flow during controlled hypotension in the pig. Acta. Anaesthesiol. Scand. 51: 607-613. [Medline] [CrossRef]

36. Kleinsasser, A., Lindner, K.H., Hoermann, C., Schaefer, A., Keller, C., and Loeckinger, A. 2001. Isoflurane and sevoflurane anesthesia in pigs with a preexistent gas exchange defect. Anesthesiology 95: 1422-1426. [Medline] [CrossRef]

37. Ko, J.C., Williams, B.L., Rogers, E.R., Pablo, L.S., McCaine, W.C., and McGrath, C.J. 1995. Increasing xylazine dose-enhanced anesthetic properties of telazol-xylazine combination in swine. Lab. Anim. Sci. 45: 290-294. [Medline]

38. Ko, J.C., Bailey, J.E., Pablo, L.S., and Heaton-Jones, T.G. 1996. Comparison of sedative and cardiorespiratory effects of medetomidine and medetomidine-butorphanol combination in dogs. Am. J. Vet. Res. 57: 535-540. [Medline]

39. Kojima, K., Nishimura, R., Mutoh, T., Takao, K., Matsunaga, S., Mochizuki, M., and Sasaki, N. 1999. Comparison of sedative effects of medetomidine-midazolam, acepromazinebutorphanol and midazolam-butorphanol in dogs. Zentralbl. Veterinarmed. A 46: 141-148. [Medline] [CrossRef]

40. Kostopanagiotou, G., Kalimeris, K., Christodoulaki, K., Nastos, C., Papoutsidakis, N., Dima, C., Chrelias, C., Pandazi, A., Mourouzis, I., and Pantos, C. 2010. The differential impact of volatile and intravenous anaesthetics on stress response in the swine. Hormones (Athens) 9: 67-75. [Medline] [CrossRef]

41. Kurita, T., Morita, K., Kazama, T., and Sato, S. 2003. Comparison of isoflurane and propofol-fentanyl anaesthesia in a swine model of asphyxia. Br. J. Anaesth. 91: 871-877. [Medline] [CrossRef]

42. Lerman, J. and Jöhr, M. 2009. Inhalational anesthesia vs total intravenous anesthesia (TIVA) for pediatric anesthesia. Paediatr. Anaesth. 19: 521-534. [Medline] [CrossRef]

43. Lewis, K.S. and Han, N.H. 1997. Tramadol: a new centrally acting analgesic. Am. J. Health Syst. Pharm. 54: 643-652. [Medline]

44. Marik, P.E. 2004. Propofol: therapeutic indications and side-effects. Curr. Pharm. Des. 10: 3639-3649. [Medline] [CrossRef]

45. Marntell, S., Nyman, G., Funkquist, P., and Hedenstierna, G. 2005. Effects of acepromazine on pulmonary gas exchange and circulation during sedation and dissociative anaesthesia in horses. Vet. Anaesth. Analg. 32: 83-93. [Medline] [CrossRef]

46. Michael Swindle, M.U.S.C.Charleston, USA Medical University of South Carolina, Charleston, USA Swine in the Laboratory: Surgery, Anesthesia, Imaging, and Experimental Techniques, 2nd ed. 2007.

47. Modesti, C., Sacco, T., Morelli, G., Bocci, M.G., Ciocchetti, P., Vitale, F., Perilli, V., and Sollazzi, L. 2006. Balanced anestesia versus total intravenous anestesia for kidney transplantation. Minerva Anestesiol. 72: 627-635. [Medline]

48. Motulsky, H. Intuitive biostatistics. New York; Oxford: Oxford University Press; 1995.

49. Nishimura, R., Kim, H., Matsunaga, S., Hayashi, K., Tamura, H., Sasaki, N., and Takeuchi, A. 1993. Comparison of sedative and analgesic/anesthetic effects induced by medetomidine, acepromazine, azaperone, droperidol and midazolam in laboratory pigs. J. Vet. Med. Sci. 55: 687-690. [Medline] [CrossRef]

50. Nöst, R., Thiel-Ritter, A., Scholz, S., Hempelmann, G., and Müller, M. 2008. Balanced anesthesia with remifentanil and desflurane: clinical considerations for dose adjustment in adults. J. Opioid. Manag. 4: 305-309. [Medline]

51. Pypendop, B. and Verstegen, J. 1999. Cardiorespiratory effects of a combination of medetomidine, midazolam, and butorphanol in dogs. Am. J. Vet. Res. 60: 1148-1154. [Medline]

52. Rogliani, P., Calzetta, L., Rendina, E.A., Massullo, D., Dauri, M., Rinaldi, B., Capuano, A., and Matera, M.G. 2013. The influence of propofol, remifentanil and lidocaine on the tone of human bronchial smooth muscle. Pulm. Pharmacol. Ther. 26: 325-331. [Medline] [CrossRef]

53. Rossi, P., De Majo, A., Mauti, A., Mauti, P., Quattrini, V., Mattei, M., Tognoni, V., Cenci, L., Manzelli, A., Di Lorenzo, N., and Gaspari, A.L. 2007. Bloodless hepatic resection with automatic bipolar radiofrequency generator and multielectrode device. Minim. Invasive Ther. Allied Technol. 16: 66-72. [Medline] [CrossRef]

54. Rossi, P., Bove, P., Montuori, M., De Majo, A., Ricciardi, E., Mattei, M., Bernardini, R., Calzetta, L., Mauti, P., Intini, L., Quattrini, V., Chiaramonte, C., and Vespasiani, G. 2014. Partial nephrectomy using radiofrequency incremental bipolar generator with multi electrode probe: experimental study in bench pig kidneys. BMC Urol. 14: 7. [Medline] [CrossRef]

55. Seeman-Lodding, H., Biber, B., Martner, J., Pontén, J., and Winsö, O. 1996. Cardiovascular responses to experimental infra-renal aortic cross-clamping. Modulating effects of isoflurane, sodium nitroprusside and milrinone. Acta. Anaesthesiol. Scand. 40: 408-415. [Medline] [CrossRef]

56. Sims, C.D., Butler, P.E., Casanova, R., Randolph, M.A., and Yaremchuk, M.J. 1997. Prolonged general anesthesia for experimental craniofacial surgery in fetal swine. J. Invest. Surg. 10: 53-57. [Medline] [CrossRef] 
57. Sinclair, M.D. 2003. A review of the physiological effects of alpha2-agonists related to the clinical use of medetomidine in small animal practice. Can. Vet. J. 44: 885-897. [Medline]

58. Smith, A.C.W.J.E. and M. M. 1997. Swindle. Anesthesia and analgesia in swine. Academic Press, San Diego.

59. Weissman, C. 1990. The metabolic response to stress: an overview and update. Anesthesiology 73: 308-327. [Medline] [CrossRef]
60. William, J.Tranquilli, J.C.T., and Kurt A. 2007. Grimm Lumb \& Jones' Veterinary Anesthesia and Analgesia. 4 edition ed., Wiley-Blackwell.

61. Zbinden, A.M., Petersen-Felix, S., and Thomson, D.A. 1994. Anesthetic depth defined using multiple noxious stimuli during isoflurane/oxygen anesthesia. II. Hemodynamic responses. Anesthesiology 80: 261-267. [Medline] [CrossRef] 